\section{A case of Shwachman-Diamond syndrome distinguished from celiac disease}

\author{
Shin-ichiro Hagiwara, Arata Watanabe \\ Division of General Pediatrics, Saitama \\ Children's Medical Center, Japan
}

\begin{abstract}
Shwachman-Diamond syndrome (SDS) is a rare, inherited, autosomal recessive disease characterized by exocrine pancreatic dysfunction, skeletal problems and varying degrees of cytopenias resulting in bone marrow dysfunction. We report the first case of SDS that was difficult to distinguish from celiac disease because this is a valuable example of the variety in SDS presentation.
\end{abstract}

\section{Introduction}

A 2-year old Japanese girl was initially diagnosed with hypoplastic myelodysplastic syndrome (MDS) and received two courses of multiagent immunosuppressive therapy. After therapy, she experienced persistent watery diarrhea with electrolyte abnormality. The results of an upper endoscopy showed characteristics of celiac disease, but a gluten-free diet proved not to have any effect. We suspected Shwachman-Diamond syndrome (SDS) because of the persistent pancytopenia and pancreatic exocrine function that remained within the lower limit of normal. She was found to have mutations in the $S B D S$ gene and a diagnosis of SDS was made.

\section{Case Report}

A young girl (two years, four months old), who was born at term after a normal pregnancy, experienced poor weight gain despite eating normally and having no signs of diarrhea. She was admitted to our hospital at the age of two years eleven months for treatment of MDS. Before hospitalization at the age of two years four months, she had been admitted for acute bronchitis and suspected MDS with pancytopenia and an abnormal bone marrow examination. She was a well-developed child with no physical abnormalities, but she was only 86.6 $\mathrm{cm}$ tall (-1.2 standard deviation) and weighed $9.6 \mathrm{~kg}$ (-2.3 standard deviation). Hemoglobin level was $10.6 \mathrm{~g} / \mathrm{dL}$, white blood cell count was
$1.89 \times 109 / \mathrm{L}$ with $51 \%$ neutrophils and $32 \%$ lymphocytes, platelet count was $168 \times 109 / \mathrm{L}$, AST was $93 \mathrm{IU} / \mathrm{L}$, ALT was $106 \mathrm{IU} / \mathrm{L}$, IgG was 2390 $\mathrm{mg} / \mathrm{dL}$, IgA was $0 \mathrm{mg} / \mathrm{dL}$, IgM was $148 \mathrm{mg} / \mathrm{dL}$. Other test results are shown in Table 1. The diagnosis made by the central review system in Japan was selective IgA deficiency and refractory cytopenia with multilineage dysplasia. Her general condition remained good, but the white blood cell count and hemoglobin level slowly decreased. After undergoing multiagent immunosuppressive therapy (horse antithymocyte globulin $15 \mathrm{mg} / \mathrm{kg}$ for five days, cyclosporine $6 \mathrm{mg} / \mathrm{kg}$ for three months, methylprednisolone $2 \mathrm{mg} / \mathrm{kg}$ the first seven days and methylprednisolone taper over 28 days), the white blood cell count and hemoglobin level increased, and she was discharged because of transfusion independence at the age of three years. Three months later she began to have watery diarrhea several times a day and started to take oral antiflatulent. Sudan stain test found no fecal fat excretion. Pancreatic exocrine function remained within normal limits and computed tomography of the abdomen showed a normal image of the pancreas. Bone marrow aspiration showed no increase in hematopoietic cellularity at the age of three years six months. At the age of three years seven months, she was readmitted to our hospital and underwent a second course of multiagent immunosuppressive therapy with antithymocyte globulin, methylprednisolone and cyclosporine. Hematopoietic recovery was observed and she became transfusion independent again at the age of four years. However, she was repeatedly hospitalized because of infections, such as acute bronchitis and acute enterocolitis. At the age of four years four months, she presented subacute hypocalcemic and hypomagnesemic tetany and was hospitalized again. Pancreatic exocrine function was within normal limits. Her condition improved after the initiation of therapy that included elemental diet, calcium chloride and magnesium hydroride preparation through a nasogastric tube. The cause of the electrolyte abnormalities was unknown. At the age of five years three months, she underwent an upper endoscopy and colonoscopy to investigate the cause of persistent watery diarrhea and electrolyte abnormalities. Diffusely scattered granular mucosa was found in the duodenum and terminal ileum (Figure 1). Pathological examination revealed severe villous atrophy and planarized mucosa. Moderate inflammatory cell infiltration in the mucosal stroma and mild lymphoid infiltration in the mucosal epithelium was detected (Figure 2). IgA, IgM, IgG positive plasma cell infiltration was found in the mucosal stroma by immunostaining. These findings were consistent with celiac disease and a gluten-free diet was started. In spite of the diet, watery diarrhea continued, and elec-
Correspondence: Shin-Ichiro Hagiwara, Division of General Pediatrics, Saitama Children's Medical Center, 2100 Magome, Iwatsuki-ku, Saitama 339-8551, Japan.

Tel. +81.48.7581811 - Fax: +81.48 .7581818$

E-mail: hagiwara.shinichiro@pref.saitama.lg.jp

Key words: Shwachman-Diamond syndrome, celiac disease, villous atrophy.

Acknowledgments: the authors would thanks Dr. Masashi Hirayama.

Conflict of interests: the authors report no potential conflict of interests.

Received for publication: 9 May 2012.

Revision received: 19 August 2012.

Accepted for publication: 20 August 2012.

This work is licensed under a Creative Commons Attribution NonCommercial 3.0 License (CC BYNC 3.0).

(C) Copyright S. Hagiwara and A. Watanabe, 2012

Licensee PAGEPress, Italy

Pediatric Reports 2012; 4:e30

doi:10.4081/pr.2012.e30

trolyte abnormalities sometimes appeared. The antiendomysial IgA antibody, antireticulin IgA antibody, and antigliadin IgA and IgG tests were all negative, and testing for anti-tissue transglutaminase (anti-tTG) antibodies was not performed. Serological testing to HLA-DQ typing showed DQ5/DQ8. We excluded the diagnosis of celiac disease because of lack of anti-tTG antibodies. At the age of five years seven months, she again had an upper endoscopy. The gluten-free diet was discontinued because there were no findings of macroscopic or microscopic improvement in the duodenum. Severe villous atrophy and planarized mucosa were found in the duodenum as had been seen by the previous endoscopy. At the age of five years nine months, no skeletal abnormalities including metaphyseal dysostosis, thoracic dystrophies, and low bone turnover osteopenia were observed by the pediatric radiologist. At the age of six years, she was administered parenteral nutrition through a central venous catheter because of persistent electrolyte abnormalities and poor nutritional status. After high-calorie infusion, electrolyte abnormalities improved and she gradually gained weight. At the age of six years four months, she was diagnosed with growth hormone deficiency by the growth hormone stimulation test and we initiated hGH treatment. At the age of seven years one month (five years after onset), genetic analyses of SDS were performed because she had MDS, chronic dyspepsia and lower limit of normal serum level of pancreatic exocrine enzymes. 
Mutations (183-184TA $>$ CT and $258+2 \mathrm{~T}>\mathrm{C}$ mutations) of the SBDS (Shwachman-BodianDiamond syndrome) gene were detected and she was diagnosed with SDS. After diagnosis, she was treated with pancreatin, and after two months a slight improvement in diarrhea and weight gain was observed. She is soon to receive a bone marrow transplant because of ongoing pancytopenia.

\section{Discussion}

SDS is a rare autosomal recessive multisystem disorder. Shwachman, Diamond, Oski and Khaw, ${ }^{1}$ from the United States, and Bodian, Sheldon and Lightwood, from Great Britain, ${ }^{2}$ in 1964 reported a series of young patients who failed to thrive in infancy, and presented exocrine pancreatic insufficiency with diarrhea and hematologic abnormalities, in particular, neutropenia but also varying degrees of anemia and thrombocytopenia. Most patients with a clinical diagnosis of SDS carry mutations in the Shwachman-Bodian-Diamond gene $(S B D S)$, but in about $5-20 \%$, no $S B D S$ mutations are identified. ${ }^{3,4}$ At diagnosis, especially when made in infancy, symptoms of exocrine pancreatic insufficiency (e.g. steatorrhea, malabsorption, failure to thrive) are always present. Ip et al. reported that serum isoamylase values remained low at all ages. ${ }^{5}$ Our patient had no digestive symptoms until the age of three years and had serum isoamylase over $30 \mathrm{IU} / \mathrm{L}$ during clinical follow up, which was an atypical clinical course for SDS. Sanna et al. reported that all patients with SBDS mutations exhibited a characteristic pattern of fatty replacement of the pancreas on magnetic resonance imaging and computed tomography. 6,7 In our case, abdominal computed tomography showed the pancreas was not enlarged and Hounsfield Units were normal. Skeletal abnormalities have also been reported in SDS and are an important factor in supporting diagnosis. Thoracic cage is practically always involved, with short ribs with broadened anterior ends and a narrow chest. ${ }^{8}$ Our patient showed no skeletal manifestations at all. It was difficult to diagnose our patient as having SDS because of diarrhea from the age of three years, and the lack of exocrine pancreatic insufficiency; pancreas and bone imaging showed no abnormalities. In SDS patients, exocrine pancreatic insufficiency is considered to be the cause of diarrhea. But our patient did not have exocrine pancreatic insufficiency. We performed endoscopic duodenal biopsy, and the histological findings showed villous atrophy and intraepithelial lymphocytosis, indicating celiac disease, despite negative screening for antiendomysial, antireticulin and antigliadin antibody. But the symptom of diarrhea together with the endoscopic findings did not improve with a gluten-free diet, excluding celiac disease as the cause of diarrhea. The patient was later confirmed as having SDS by genetic testing which suggested that villous atrophy caused by SDS was involved in the severe diarrhea.

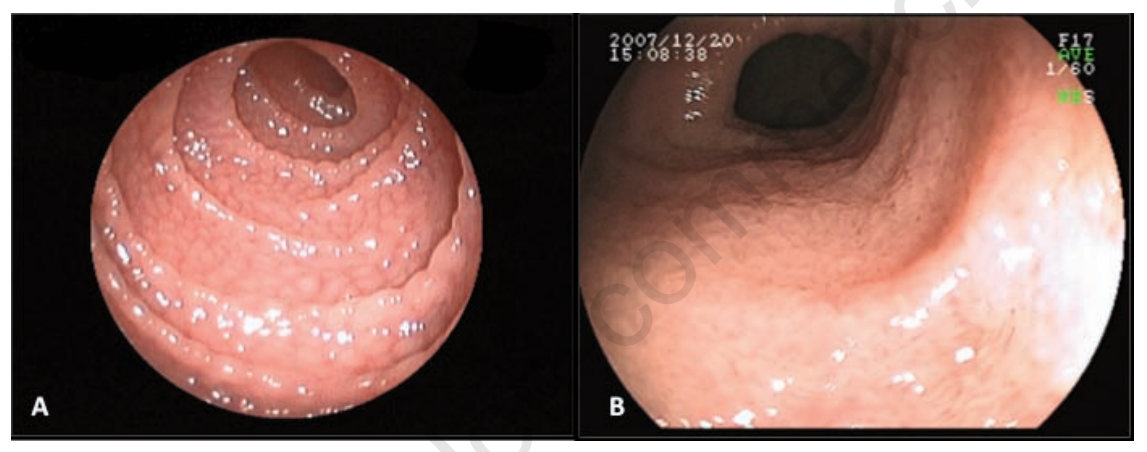

Figure 1. Endoscopic view: diffusely-scattered granular mucosa in (A) duodenum and (B) terminal ileum.

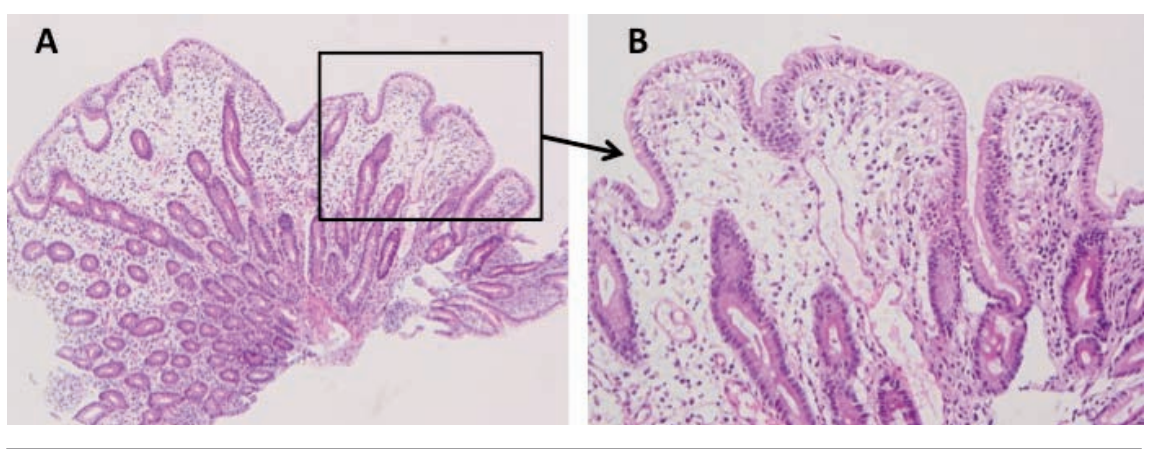

Figure 2. Histologic examination of specimens from the duodenum taken during initial upper endoscopy: A) villous atrophy and planarized mucosa is seen (Haematoxylin and Eosin staining used, original magnification 4x); B) lymphocytic and inflammatory cell infiltration are seen (Haematoxylin and Eosin staining, original magnification 10x).
Table 1. Laboratory data on first admission.

\begin{tabular}{lc} 
Hemoglobin & $10.6 \mathrm{~g} / \mathrm{dL}$ \\
Pancreatic enzymes & $66 \mathrm{U} / \mathrm{L}$ \\
Amylase & $220 \mathrm{ng} / \mathrm{mL}$ \\
Trypsin & $15 \mathrm{U} / \mathrm{L}$ \\
Lipase & $1180 \mathrm{ng} / \mathrm{dL}$ \\
\hline Elastase & $1890 \mathrm{per} \mathrm{mm}{ }^{3}$ \\
\hline White-cell count & $15 \%$ \\
Differential count & $32 \%$ \\
Neutrophils & $0 \%$ \\
\hline Lymphocytes & $8 \% 0$ \\
Blastocytes & $1680 / \mathrm{L}$ \\
\hline Reticulocytes & $93 \mathrm{U} / \mathrm{L}$ \\
Platelates & $106 \mathrm{U} / \mathrm{L}$ \\
\hline AST & $245 \mathrm{U} / \mathrm{L}$ \\
ALT & $2390 \mathrm{mg} / \mathrm{dL}$ \\
\hline LDH & $148 \mathrm{mg} / \mathrm{dL}$ \\
IgG & $0 \mathrm{mg} / \mathrm{dL}$ \\
\hline IgM & $3.7 \mathrm{ng} / \mathrm{mL}$ \\
IgA & $55 \mathrm{pg} / \mathrm{mL}$ \\
\hline Serum folic acid & $0.01 \mathrm{mg} / \mathrm{dL}$ \\
\hline Serum B12 & $n e g a t i v e$ \\
\hline CRP & $n e g a t i v e$ \\
Anti-endomysium IgA antibody & $n e g a t i v e$ \\
\hline Anti-reticulin IgA antibody & $\mathrm{DQ} 5 / \mathrm{DQ} 8$ \\
\hline Anti-gliadin IgA and IgG antibody
\end{tabular}

AST, aspartate aminotransaminase; ALT, alanine aminontransaminsas; LDH, lactate dehydrogenase; Ig, immunoglobulin; CRP, C-reactive protein. 


\section{Conclusions}

To the best of our knowledge, this is the first report of an SDS patient presenting villous atrophy. This is an unusual and extremely useful case in that it suggests a variety of clinical conditions in SDS. We recommend considering the possibility of SDS even if there is no evidence of exocrine pancreatic insufficiency, abnormal pancreatic imaging, or skeletal abnormalities when the patient has MDS and fails to thrive. SDS should also be included in the differential diagnosis when a gluten-free diet does not improve the clinical symptoms for a case with histological intestinal features of celiac disease. Intestinal involvement may be genetic because symptoms associated with celiac disease did not improve with multiagent immunosuppressive therapy and a gluten-free diet.

\section{References}

1. Shwachman H, Diamond LK, Oski FA, et al. The syndrome of pancreatic insufficiency and bone marrow dysfunction. $\mathrm{J}$ Pediatr 1964;65:645-63.

2. Bodian M, Sheldon W, Lightwood R. Congenital hypoplasia of the exocrine pancreas. Acta Paediatr 1964;53:282-93.

3. Boocock GR, Morrison JA, Popovic M, et al. Mutations in SBDS are associated with Shwachman-Diamond syndrome. Nat Genet 2003;33:97-101.

4. Woloszynek JR, Rothbaum RJ, Rawls AS, et al. Mutations of the SBDS gene are present in most patients with Shwachman-Diamond syndrome. Blood 2004; 104:3588-90.

5. Ip WF, Dupuis A, Ellis L, et al. Serum pan- creatic enzymes define the pancreatic phenotype in patients with ShwachmanDiamond syndrome. J Pediatr 2002; 141:259-65.

6. Toiviainen-Salo S, Raade M, Durie PR, et al. Magnetic resonance imaging findings of the pancreas in patients with Shwachman-Diamond syndrome and mutations in the SBDS gene. J Pediatr 2008;152:434-6.

7. Bom EP, van der Sande FM, Tjon RT, et al. Shwachman syndrome: CT and MR Diagnosis. J Comput Assist Tomogr 1993;17:474-6.

8. McLennan TW, Steinbach HL. Shwachman's syndrome: the broad spectrum of bony abnormalities. Radiology 1974; 112:167-73. 